\title{
Bactericidal Effect of Different Anti- Microbial Agents on Fusobacterium Nucleatum Biofilm
}

\author{
Rupa Ashok ${ }^{1}$, Arathi Ganesh ${ }^{1}$, Kandaswamy Deivanayagam ${ }^{1}$ \\ 1. Department of Conservative Dentistry and Endodontics, Faculty of Dental Sciences, Sri Ramachandra \\ University, Porur, Chennai, India
}

$\square$ Corresponding author: Rupa Ashok, rupa@sriramachandra.edu.in

Disclosures can be found in Additional Information at the end of the article

\section{Abstract}

\section{Introduction}

The root canal anatomy of the teeth is very complex. Complete debridement of the root canals is a challenge and is very important for the success of the root canal treatment. Hence, this study was done to find an effective irrigant which can be used during root canal treatment.

\section{Objective}

The bactericidal effect of a potential root canal irrigant was compared with two commonly used root canal irrigants against monoculture biofilm of a commercially available isolate of Fusobacterium nucleatum.

\section{Methods}

A monoculture biofilm of Fusobacterium nucleatum was grown on glass slides. The glass slides containing the biofilm were immersed in centrifuge tubes containing $5 \%$ sodium hypochlorite, 2\% Chlorhexidine, $6 \%$ turmeric solution, $9 \%$ turmeric solution and distilled water for a time span of one minute. A wire loop was used to scrape off the biofilms onto sterile brain heart infusion agar plates. This was further subjected to an incubation period of 96 hours at $37^{\circ} \mathrm{C}$. Colony forming units were quantified by statistical analysis and results were obtained.

\section{Results}

The anti-bacterial activity of $6 \%$ and $9 \%$ turmeric solution was statistically significant against Fusobacterium nucleatum when compared to $2 \%$ Chlorhexidine and $5 \%$ sodium hypochlorite.

Received 05/12/2017 Review began 06/06/2017 Review ended 06/06/2017 Published 06/11/2017

C) Copyright 2017

Ashok et al. This is an open access article distributed under the terms of the Creative Commons Attribution License CC-BY 3.0., which permits unrestricted use, distribution, and reproduction in any medium, provided the original author and source are credited.

\section{Conclusion}

In endodontic treatment, turmeric solution may be considered as an effective irrigant.

Categories: Miscellaneous

Keywords: fusobacterium nucleatum, turmeric solution, sodium hypochlorite, chlorhexidine, root canal irrigant

\section{Introduction}

Root canal serves as a microenvironment for several microbial species to form dense bacterial 
biofilms and cause persistent infections [1]. The necrotic and infected pulp provides an ideal habitat for the microorganisms [2]. Providing a hermetic seal of the root canal space thereby averting secondary infection, while simultaneously trying to eradicate or reduce the root canal microbiota is the ultimate goal of endodontic treatment [3]. Microorganisms in the root canals occur in various forms, namely as planktonic, clusters and as biofilms. Biofilm consists of communities of microorganisms that are firmly fixed in extracellular polymeric substance and they are attached onto a surface [1,3]. Microorganisms, which are found freely suspended in an aqueous medium, are called planktons [4]. Biofilms are established by microorganisms for enhancing protection and their physiologic functions. They strongly resist the host immune response and antimicrobial agents. Bacteria within biofilms have increased potential to resist adverse conditions such as nutritional distress, acidic or alkaline environment and antimicrobials than planktonic bacteria [3]. The microorganisms in the biofilms are around more than thousand times resistant to antimicrobial agents than planktonic forms [5].

Fusobacterium nucleatum is a gram-negative, obligate anaerobic rod, non-sporing oral bacterium occurring normal flora in the mouth. It is highly pathogenic, as it produces tissue irritants and are usually found in periodontal lesions, synergistically acting with other types of bacteria [6]. Increased pathogenicity has been observed when there is combination of anaerobes like prevotella, porphyromonas and fusobacterium genera [7]. Gomes, et al. [8] reported that fusobacterium species was associated with specific signs and symptoms of endodontic origin such as pain, tenderness on percussion, wet canals, and in purulent exudates. Hence, it has become necessary to study the influence of irrigants on monoculture biofilms of Fusobacterium nucleatum to prevent oral and systemic infections.

Ability to remove organic and inorganic debris, possessing reduced toxicity, ability to lubricate effectively while simultaneously eradicating the smear layer to completely disinfect the root canal are some of the ideal requirements of an ideal irrigant [9]. Sodium hypochlorite and Chlorhexidine possess many properties of an ideal irrigant. However, previous studies have shown variations regarding the anti-microbial potential of sodium hypochlorite and Chlorhexidine [10-11]. Literature has revealed that turmeric (rhizomes of curcuma longa) when used as an antimicrobial agent has been very effective against gram-positive and gramnegative bacteria that are known to cause infections such as pneumonia, skin diseases, urinary tract infections, and meningitis in human beings [12-14]. Very few studies have been carried out with turmeric solution against endodontic infections. Hence, this study was done to compare the anti-bacterial effectiveness of conventional irrigants such as $5 \%$ sodium hypochlorite and $2 \%$ Chlorhexidine, along with a novel potential irrigant at two different concentrations, $6 \%$ and $9 \%$ turmeric solution on Fusobacterium nucleatum biofilm.

\section{Materials And Methods}

An isolate of Fusobacterium nucleatum ATCC 25586 (Microbiologies MN) was obtained. Brain heart infusion broth (BHIB) (HiMedia Laboratories, India) was used to prepare broth cultures for the biofilm experiment. Sterile glass microscope slides were immersed in $35 \mathrm{ml}$ of BHIB in sterile centrifuge tubes. These tubes were later inoculated with $2.5 \mathrm{ml}$ of the broth and were further incubated for 96 hours at $37^{\circ} \mathrm{C}$. Thus, the biofilm development was seen in the prepared biofilm model.

The irrigants used in this study were Group I - 2\% Chlorhexidine (Ammdent, India); Group II 5\% Sodium Hypochlorite (Prime Dental, Thane); Group III - 6\% turmeric solution; Group IV 9\% turmeric solution and Group V - sterile distilled water. Group I, II, and V were commercially available. Group III and IV were prepared. Turmeric solution was obtained from the curcuma longa rhizomes by maceration method and rota evaporation was used to concentrate the extract. Concentrations of $6 \%$ and $9 \%$ turmeric solutions were obtained by mixing 6 and 9 grams of turmeric extract in $100 \mathrm{ml}$ of sterile distilled water respectively. Sterile distilled water 


\section{Cureus}

was used to wash carefully the glass slides with biofilm, which were removed from the centrifuge tubes. The slides with biofilm were then fully submerged in Petri dishes containing $35 \mathrm{ml}$ of each of the five groups with 10 slides in each group for an exposure time of one minute and were immediately removed [15]. These slides were further dipped in Petri dishes containing neutralizing broth (Difco Laboratories, Michigan) supplemented with $0.5 \%$ Tween 20 (HiMedia Laboratories, India) to stop the antibacterial reaction of the irrigants. Following this, the slides were dipped in $10 \mathrm{ml}$ of sterile BHIB in Petri dishes and biofilms were scraped from the surfaces of the slide with the help of a wire loop. The scraped biofilms were inoculated on brain heart infusion agar plates and incubated at $37^{\circ} \mathrm{C}$ for 96 hours in an anaerobic jar. The number of colony forming units in each plate was calculated to quantify the viable bacteria. Kruskal-Wallis test and Mann-Whitney U test using SPSS 15 software (IBM, Armonk, NY) were utilized to statistically analyse the data and to calculate statistically significant differences ( $\mathrm{p}<$ 0.001).

\section{Results}

The results were analyzed from the data obtained. A significant reduction of viable bacteria in the biofilm was seen in Groups I, II, III, and IV when compared to Group V (sterile distilled water). Group IV (9\% turmeric solution) showed an overall statistically significant reduction (p $<0.001$ ) of viable bacteria among all the groups. Group III (6\% turmeric solution) showed a statistically significant reduction when compared to Group I ( $2 \%$ Chlorhexidine) and Group II (5\% Sodium hypochlorite). Group II showed a greater reduction than Group I, however, it was not statistically significant between the two groups. Table 1 shows the significant bacterial reduction when $9 \%$ turmeric solution was used.

\begin{tabular}{|c|c|c|c|c|c|c|}
\hline \multirow{2}{*}{ Groups } & \multicolumn{3}{|c|}{ log cfu/slide } & \multirow{2}{*}{ H-value } & \multirow{2}{*}{ p-value } & \multirow{2}{*}{ Comparisons among the groups } \\
\hline & Mean & Std. deviation & Median & & & \\
\hline Group I & 3.441 & 0.031 & 3.447 & \multirow{5}{*}{46.026} & \multirow{5}{*}{$<0.001$} & 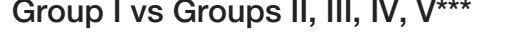 \\
\hline Group II & 3.260 & 0.162 & 3.327 & & & 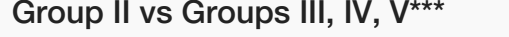 \\
\hline Group III & 1.660 & 1.450 & 3.349 & & & Group III vs Group IV*^ \\
\hline Group IV & 0.000 & 0.000 & 0.000 & & & 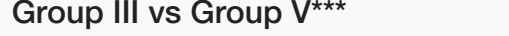 \\
\hline Group V & 3.549 & 0.013 & 3.544 & & & Group IV vs Group V*** \\
\hline
\end{tabular}

\section{TABLE 1: Statistical analysis using Kruskal-Wallis test and Mann-Whitney U test.}

${ }^{\star \star *} \mathrm{p}<0.001$

${ }^{* *} p<0.01$

Group I: Chlorhexidine (2\%), Group II: Sodium hypochlorite (5\%), Group III: Turmeric solution (6\%), Group IV: Turmeric solution (9\%), Group V: Sterile distilled water, cfu: colony forming unit.

\section{Discussion}

The Fusobacterium nucleatum has the ability to form aggregates with other pathogenic bacteria in periodontal disease and it also acts as a connecting medium between early and late colonizers [6]. It is found in other body sites causing infections and was also found to be linked with severe forms of inter-appointment endodontic flare-ups [16]. Numerous studies have been 
done to find the microbes in the root canals and Fusobacterium nucleatum has been found in $44 \%$ of the cases [17]. Biofilm model was used in this study since bacteria are generally found in the root canal as biofilms and also because the behavior of bacteria in the biofilm is different from their planktonic counterparts [5]. The biofilm model used in this study had been previously used to test four antimicrobial irrigants against E. faecalis [15]. Many previous studies $[5,15]$ on bacterial biofilms have used counting of colony forming units to obtain satisfactory results. Hence, the same methodology has been utilized in this study.

A study done by Williamson, et al. has shown sodium hypochlorite to exhibit statistically significant reduction in colony forming units at one minute of exposure [15]. Therefore, our study also utilized a similar type of exposure time for the various irrigants. In a pilot study done, $3 \%$ turmeric solution was found to be ineffective against E. faecalis. Hence, $6 \%$ and $9 \%$ concentrations of turmeric solution were used. In our study, it was found that $9 \%$ turmeric solution (Group IV) was significantly better in eradicating the biofilm than the other groups. There was no significant difference between $2 \%$ Chlorhexidine and 5\% Sodium hypochlorite.

The active component in turmeric is called curcumin which is a polyphenolic compound found in it inherently. FtsZ, a prokaryotic homologue of eukaryotic cytoskeletal protein tubulin, polymerizes to form a Z-ring at the mid cell that brings about bacterial cell division. Rai, et al. found that curcumin increased the GTPase activity of FtsZ which disrupts the Z-ring formation and inhibits bacterial cytokinesis by inhibiting FtsZ assembly [18].

Sodium hypochlorite was effective in disrupting the biofilm to a certain level, which may be due to its tissue dissolving properties causing complete cellular dissolution [19]. But, the antibacterial activity of sodium hypochlorite in this study was not as statistically significant as turmeric solution. Studies comparing sodium hypochlorite and chlorhexidine, have found the former to be better than chlorhexidine in antimicrobial property [20-21]. Spratt, et al. found that sodium hypochlorite could not completely eradicate Fusobacterium nucleatum biofilm even after 15 minutes exposure [21]. In a study done by Clegg, et al., it was found that chlorhexidine killed bacteria but failed to disrupt biofilm [22]. In another study by Vitkov, et al., it was found that the efficiency of chlorhexidine was insufficient in causing biofilm disintegration [23].

As turmeric solution showed to be very effective against Fusobacterium nucleatum biofilm, further studies can be done on other microorganisms.

\section{Conclusions}

Among the antimicrobial agents used in this study, 9\% turmeric solution showed a significant bactericidal activity against Fusobacterium nucleatum biofilm. Thus, it has been found that turmeric solution is able to penetrate the biofilm and destroy Fusobacterium nucleatum and can hence be considered as an effective irrigant in endodontic therapy.

\section{Additional Information Disclosures}

Human subjects: All authors have confirmed that this study did not involve human participants or tissue. Animal subjects: All authors have confirmed that this study did not involve animal subjects or tissue. Conflicts of interest: In compliance with the ICMJE uniform disclosure form, all authors declare the following: Payment/services info: All authors have declared that no financial support was received from any organization for the submitted work. Financial relationships: All authors have declared that they have no financial relationships at present or within the previous three years with any organizations that might have an interest in 
the submitted work. Other relationships: All authors have declared that there are no other relationships or activities that could appear to have influenced the submitted work.

\section{References}

1. Nair PNR: On the causes of persistent apical periodontitis: a review . Int Endod J. 2006, 39:249-281. 10.1111/j.1365-2591.2006.01099.x

2. Fabricus L, Dahlén G, Ohman AE, et al.: Predominant indigenous oral bacteria isolated from infected root canal after varied times of closure. Scan J Den Res. 1982, 90:134-144. 10.1111/j.1600-0722.1982.tb01536.x

3. Nair PNR, Henry S, Cano V, et al.: Microbial status of apical root canal system of human mandibular first molars with primary apical periodontitis after "one-visit" endodontic treatment. Oral Surg Oral Med Oral Pathol Oral Radiol Endod. 2005, 99:231-52. 10.1016/j.tripleo.2004.10.005

4. Costerton $\mathrm{W}$, Veeh R, Shirtliff M, et al.: The application of biofilm science to the study and control of chronic bacterial infections. J Cli Inv. 2003, 112:1466-1477. 10.1172/JCI20365

5. Wilson M: Susceptibility of oral biofilms to anti microbial agents. J Med Microbiol. 1996, 44:79-87. 10.1099/00222615-44-2-79

6. Bolstad AI, Jensen HB, Bakken V: Taxonomy, biology and periodontal aspects of Fusobacterium nucleatum. Cli Microbiol Rev. 1996, 9:55-71.

7. Johnson EM, Flannagan SE, Sedgley CM: Coaggregation interactions between oral and endodontic enterococcus faecalis and bacterial species isolated from persistent apical periodontitis. J Endod. 2006, 32:946-950. 10.1016/j.joen.2006.03.023

8. Gomes BP, Pinheiro ET, Gadê-Neto CR, et al.: Microbiological examination of infected dental root canals. Oral Microb Immunol. 2004, 19:71-76. 10.1046/j.0902-0055.2003.00116.x

9. Zehnder M: Root canal irrigants. J Endod. 2006, 32:389-398. 10.1016/j.joen.2005.09.014

10. Jeansonne MJ, White RR: A comparison of $2 \%$ chlorhexidine gluconate and $5.25 \%$ sodium hypochlorite as antimicrobial endodontic irrigants. J Endod. 1994, 20:276-278. 10.1016/S0099-2399(06)80815-0

11. Giardino L, Ambu E, Savoldi E, et al.: Comparative evaluation of antimicrobial efficacy of sodium hypochlorite, MTAD, and tetraclean against enterococcus faecalis biofilm. J Endod. 2007, 33:852-855. 10.1016/j.joen.2007.02.012

12. Ruby AJ, Kuttan G, Babu KD, et al.: Anti-tumour and antioxidant activity of natural curcuminoids. Cancer Lett. 1995, 94:79-83. 10.1016/0304-3835(95)03827-J

13. Dorai T, Aggarwal BB: Role of chemopreventive agents in cancer therapy . Cancer Lett. 2004, 215:129-140. 10.1016/j.canlet.2004.07.013

14. Mishra S, Narain U, Mishra K, et al.: Design, development and synthesis of mixed bioconjugates of piperic acid-glycine, curcumin-glycine/alanine and curcumin-glycinepiperic acid and their antibacterial and antifungal properties. Bioorg Med Chem. 2005, 13:1477-1486. 10.1016/j.bmc.2004.12.057

15. Williamson AE, Cardon JW, Drake DR: Antimicrobial susceptibility of monoculture biofilms of a clinical isolate of Enterococcus faecalis. J Endod. 2009, 35:95-97. 10.1016/j.joen.2008.09.004

16. Chávez de Paz Villanueva LE: Fusobacterium nucleatum in endodontic flare-ups. Oral Surg Oral Med Oral Pathol Oral Radiol Endod. 2002, 93:179-183. 10.1067/moe.2002.120803

17. Rocas IN, Siqueira JF Jr: Root canal microbiota of teeth with chronic apical periodontitis . Cli Microbiol . 2008, 46:3599-3606. 10.1128/JCM.00431-08

18. Rai D, Singh JK, Roy N, et al.: Curcumin inhibits FtsZ assembly: an attractive mechanism for its antibacterial activity. Biochem J. 2008, 410:147-155. 10.1042/BJ20070891

19. Moorer WR, Wesselink PR: Factors promoting the tissue dissolving capability of sodium hypochlorite. Int Endod J . 1982, 15:187-196. 10.1111/j.1365-2591.1982.tb01277.x

20. Bryce G, O'Donnell D, Ready D, et al.: Contemporary root canal irrigants are able to disrupt and eradicate single- and dual- species biofilms. J Endod. 2009, 35:1243-1248. 10.1016/j.joen.2009.05.034

21. Spratt DA, Pratten J, Wilson M, et al.: An in vitro evaluation of the antimicrobial efficacy of irrigants on biofilms of root canal isolates. Int Endod J. 2001, 34:300-307. 10.1046/j.13652591.2001.00392.x

22. Clegg MS, Vertucci FJ, Walker C, et al.: The effect of exposure to irrigant solutions on apical 


\section{Cureus}

dentin biofilms in vitro. J Endod. 2006, 32:434-437. 10.1016/j.joen.2005.07.002

23. Vitkov L, Hermann A, Krautgartner WD, et al.: Chlorhexidine-induced ultrastructural alterations in biofilm. Microsc Res Tech. 2005, 68:85-89. 10.1002/jemt.20238 